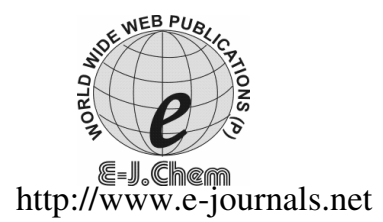

\title{
Synthesis and Characterization of Titanium Supported on High Order Nanoporous Silica and Application for Direct Oxidation of Benzene to Phenol
}

\author{
ALIREZA BADIEI*, JAVAD GHOLAMI and YEGANEH KHANIANI \\ School of Chemistry, College of Science, \\ University of Tehran, Iran \\ abadiei@khayam.ut.ac.ir
}

Received 8 May 2009; Accepted 5 July 2009

\begin{abstract}
Direct oxidation of benzene to phenol in liquid phase by $\mathrm{H}_{2} \mathrm{O}_{2}$ peroxide was examined over Ti/ LUS-1 catalyst in methanol and acetic acid as solvents. The maximum yield and selectivity of the phenol produced was obtained in the presence of acetic acid. It can be attributed to the stabilization of $\mathrm{H}_{2} \mathrm{O}_{2}$ as peroxy acetic acid species in the radical mechanism for this reaction. Acetic acid interacts with hydrogen peroxide over Ti/LUS-1 and produces acetoxy radicals.
\end{abstract}

Keywords: Nanoporous silica, LUS-1, Titanium, Oxidation catalyst.

\section{Introduction}

Nanoporous materials nowadays cover a broad range of economically very important processes related to the upgrading of crude oil and natural gas as well as the profitable production of fine chemicals ${ }^{1}$. All reactions and conversions are based on the acid and redox properties and shape-selective behavior of nanoporous materials. The most common reactions, where nanoporous catalysts are involved, are fluid catalytic cracking, hydrocracking, aliphatic alkylation, isomerisation, oligometisation, transformation of aromatics, alcohols and amines since these reactions can be performed under mild condition in the liquid phase.

The field of porous titanium silicates is one of the fastest developing areas of porous materials ${ }^{2}$. The materials possess remarkable catalytic activity in selective oxidation of organic compounds. Microporous titanium silicates such as zeolites Ti-silicalite-1 and Ti-Beta are extremely efficient catalysts for epoxidation of alkenes in the presence of aqueous $\mathrm{H}_{2} \mathrm{O}_{2}$ and tert-butyl hydroperoxide as oxidants, which is attributed to the unique architecture of titanium centres that are isolated in the silicate framework ${ }^{3}$. The dimensions of micropores within zeolitic structures limit the application of these catalysts to catalytic reactions with small molecules. Larger reactants could in principle be processed by using mesoporous titanium silicates such as Ti-MCM-41 or Ti-SBA- $15^{4}$. 
In the present study, hydroxylation of benzene to phenol with hydrogen peroxide has been carried out using titanium supported on LUS-1 nanoporous silica. Phenol is an important intermediate for the manufacture of petrochemicals, agrochemicals and plastics which is currently carried out through the Cumene process or toluene oxidation. The economics of this process has a large extent dependent on the marketability of acetone (as a byproduct) ${ }^{5}$. In the first step of the study, titanium catalysts containing $\mathrm{TiO}_{2}$ species on high surface area supports of LUS-1 were synthesis and characterized and in second step using of for direct oxidation of benzene to phenol with hydrogen peroxide in the liquid phase.

\section{Experimental}

Silica gel( 60), sodium hydroxide, $n$-decane, titanium trichloride, carbon tetrachloride, benzene, hydrogen peroxide(30\%) and the quaternary ammonium surfactant $N$-acetyl- $n, n, n$ trimethylamoniumbromid were obtained from Merck Chemicals, co surfactant $p$-toluenesulfonic acid monohydrate were obtained from Aldrich. All chemicals were used as received.

\section{Synthesis}

The preparation methods of the following nanoporous silica LUS-1 were described in previous report ${ }^{6}$. About $3 \mathrm{~g}$ of uncalcined LUS-1 was stirred in $60 \mathrm{~mL}$ of carbon tetrachloride solution containing $\mathrm{TiCl}_{3}$ for $24 \mathrm{~h}$ in atmosphere of argon and temperature of $70{ }^{\circ} \mathrm{C}$. Then the product was filtered and washed with carbon tetrachloride to remove the excess metal complexes. The filtered samples were dried under vacuum and these final products were denoted.

\section{Results and Discussion}

Figure 1 shows the XRD patterns of LUS- 1 samples before and after loading of $\mathrm{TiO}_{2}$. The $\mathrm{TiO}_{2}$ contained LUS-1 samples will exhibit their characteristic peaks assignable to hexagonal $P 6 \mathrm{~mm}$ symmetry for LUS-1 sample. The spectra display the hexagonal symmetry with (100), (110) and (200) diffraction peaks. The (100) diffraction peak indicates welldefined mesostructure (pore diameter 2-50 nm) solid supports and the XRD patterns show that the loading of $\mathrm{TiO}_{2}$ on LUS-1 in solution do not affect the ordered of mesostructure.

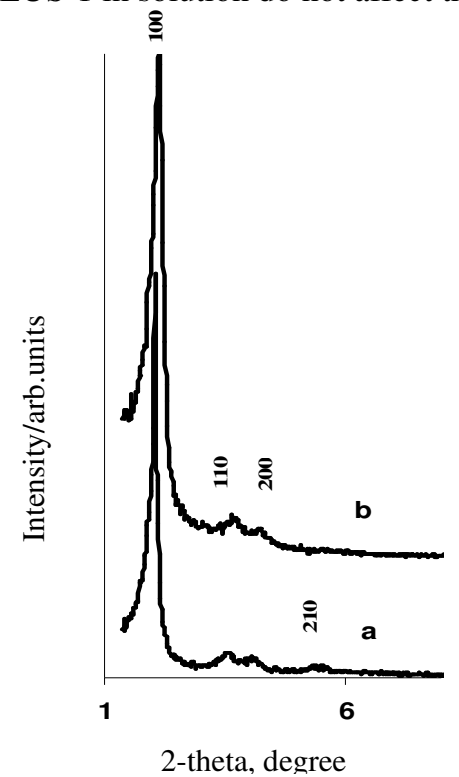

Figure 1. XRD patterns of a) LUS-1 b)Ti /LUS-1. 
The nitrogen adsorption-desorption isotherms for LUS-1 and Ti/LUS-1 are shown in Figure 2. Both materials show type-IV adsorption behavior with the hysteresis loops appearing at relatively high pressure, suggesting that the prepared samples have regular mesoporous framework structures. Their texture properties are given in Table 1 . The surface area, average pore diameter calculated by the BET method and pore volume of Ti/LUS-1 are $800 \mathrm{~m}^{2} \mathrm{~g}^{-1}, 4.21 \mathrm{~nm}$ and $0.4267 \mathrm{~cm}^{3} \mathrm{~g}^{-1}$, respectively, which are smaller than those of LUS-1 due to the deposition of titanium oxide into the pores.

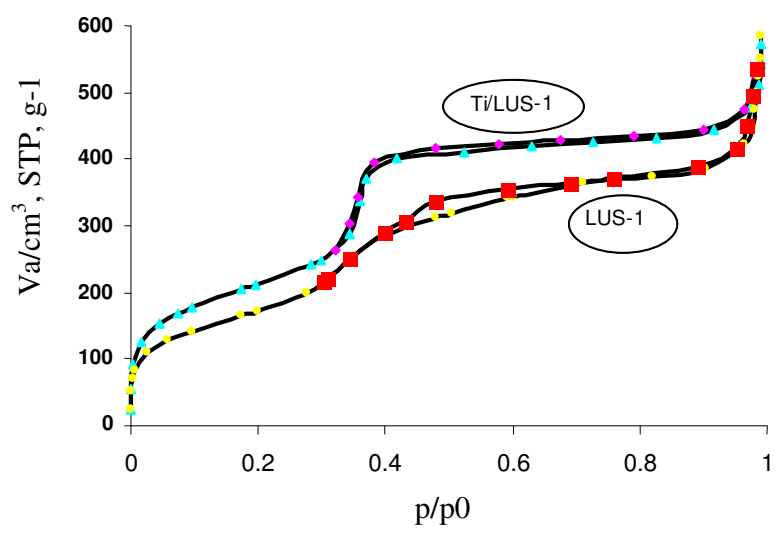

Figure 2. Nitrogen adsorption-desorption isotherms of LUS-1 and Ti/LUS-1.

Table 1. Surface area, pore size, and pore volume of $\mathrm{Ti}$ incorporated in the uncalcined samples of LUS-1 before and after the loading.

\begin{tabular}{lccc}
\hline Name & $\begin{array}{c}\text { Surface area, } \\
\mathrm{m}^{2} / \mathrm{g}\end{array}$ & $\begin{array}{c}\text { Pore volume, } \\
\mathrm{cm}^{3} / \mathrm{g}\end{array}$ & $\begin{array}{c}\text { Average pore } \\
\text { diameter, } \mathrm{nm}\end{array}$ \\
\hline LUS-1 & 900 & 0.85 & 4.3 \\
Ti/LUS-1 & 800 & 0.80 & 4.2 \\
\hline
\end{tabular}

The nature of titanium species on the Ti/LUS-1 was studied by UV-vis spectroscopy (Figure 3). It generally provides valuable information about the coordination environments and oxidation states of titanium. The UV-vis shows three bands at $c a$. 220 and $282 \mathrm{~nm}$. The band at $220 \mathrm{~nm}$ can be attributed to charge transfer (CT) between $\mathrm{O}^{2-}$ and a center $\mathrm{Ti}^{4+}$ ion, as already observed for centers in zeolitic structures. The band at lower energy $(282 \mathrm{~nm})$ can be ascribed to distorted octahedral $\mathrm{Ti}^{4+}$ species. Furthermore, the semi-quantitative calculations of the peak fitting values shows that titanium species in Ti/ LUS-1 exist mostly in tetrahedral $\mathrm{Ti}$ and much less in octahedral ${ }^{7-8}$. The texture results and UV-Vis indicated that titanium species are easily accessible to organic molecules. Thus, Ti/ LUS-1 with high oxidation state of titanium can be a good candidate for redox catalytic reaction.

\section{Catalytic activities}

The catalytic activities were evaluated by the reaction of benzene and hydrogen peroxide $30 \%$ using various compounds as a solvent under reflux. A typical catalytic condition is the following: $0.1 \mathrm{~g}$ of catalyst was placed in a $50 \mathrm{~mL}$ round bottom flask with a condenser, and then $1 \mathrm{~mL}$ of benzene in $11 \mathrm{~mL}$ of solvent was added. The mixture was stirred for $5 \mathrm{~min}$, then $2 \mathrm{~mL}$ of $\mathrm{H}_{2} \mathrm{O}_{2}\left(30 \%\right.$ in aqueous solution) were added. After one day heated in $60{ }^{\circ} \mathrm{C}$, the solid was filtered and analyzed by GC. 


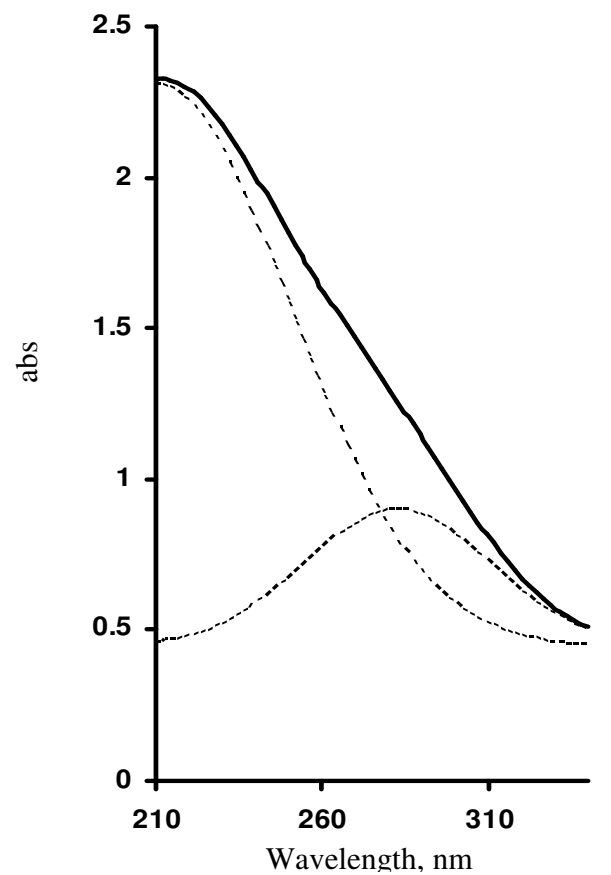

Figure 3. UV-vis spectra of Ti / LUS-1.

Catalytic hydroxylation of benzene over $\mathrm{TiO}_{2}$ species supported on LUS- 1 samples by hydrogen peroxide $(30 \%)$ in acetic acid and methanol was investigated. The oxidation yield of benzene is $5 \%$ and $1 \%$ in acetic acid and methanol, respectively. Selectivity for phenol production is around $90 \%$.

The yield and selectivity of the phenol in the presence of acetic acid was higher than the methanol. It can be attributed to the stabilization of $\mathrm{H}_{2} \mathrm{O}_{2}$ as peroxy acetic acid species in the radically mechanism. We can suggest that acetic acid interact with hydrogen peroxide over Ti/LUS- 1 and produce acetoxy radicals. These radicals may attack of the benzene and output benzyl radicals in the next section reaction by hydroxyl radical's genesis of decomposition of hydrogen peroxide over titanium segment and produced phenol $^{9-10}$.

\section{Conclusion}

Ti-LUS-1 was synthesized and characterized of showed ordered structural patterns for the catalyst prepared. Direct oxidation of benzene to phenol in liquid phase by $\mathrm{H}_{2} \mathrm{O}_{2}$ peroxide was examined over this catalyst in methanol and acetic acid as solvent. The maximum yield and selectivity of the phenol produced was obtained in the presence of acetic acid. It can be attributed to the stabilization of $\mathrm{H}_{2} \mathrm{O}_{2}$ as peroxy acetic acid species in the radically mechanism for this reaction. We suggest that acetic acid and hydrogen peroxide interaction over Ti/LUS-1 leads to acetoxy radicals.

\section{References}

1 Sing K S W, Everett D H, Haul R A W, Moscou L, Pierotti R A, Rouquerol J and Siemieniewska T, Pure Appl Chem., 1985, 57, 603.

2 Vayssilov G N, Catal Rev Sci Eng., 1997, 39, 209. 
3 Lamberti C, Bordiga S, Arduino D, Zecchina A, Geobaldo F, Spanó G, Carati A, Villian F and Vlaic G, J Phys Chem B., 1998, 102, 6382.

4 Trukhan N N, Romannikov V N, Shmakov A N, Vanina M P, Paukshtis E A, Bukhtiyarov V I, Kriventsov V V, Danilov I Y and Kholdeeva O A, Micropor Mesopor Mater., 2003, 59, 73.

5 Niwa S, Eswaramoorthy M, Nair J, Raj A, Itoh N, Shoji H, Namba T and Mizukami F, Science, 2002, 295, 105.

6 Bonneviot L, Badiei A and Crowther N, WO 02/16267, 2001 (Word Patent).

7 Begona J f, Machetti S G, Gallegos N G, Alvarez A M, Cagnoli M V and Yeramian A A, Micropor Mesopor Mater., 1998, 24, 163.

8 Kovalenko A S, Ilian V G and Filippov A P, Theor Exp Chem., 2000, 36, 123.

9 Iwamoto M, Hirata J, Matsukami K and Kagawa S J, Phys Chem., 1983, 87, 903.

10 Dapurkar S E, Sakthivel A and Selvam P, J Molc Catal A: Gen., 2004, 223, 241. 


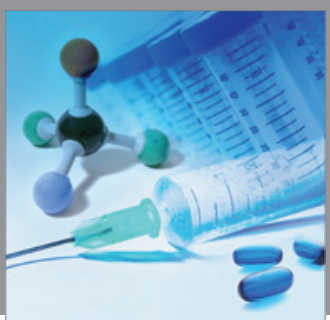

International Journal of

Medicinal Chemistry

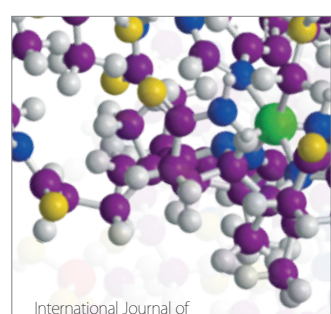

Carbohydrate Chemistry

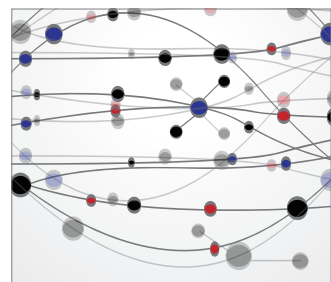

The Scientific World Journal
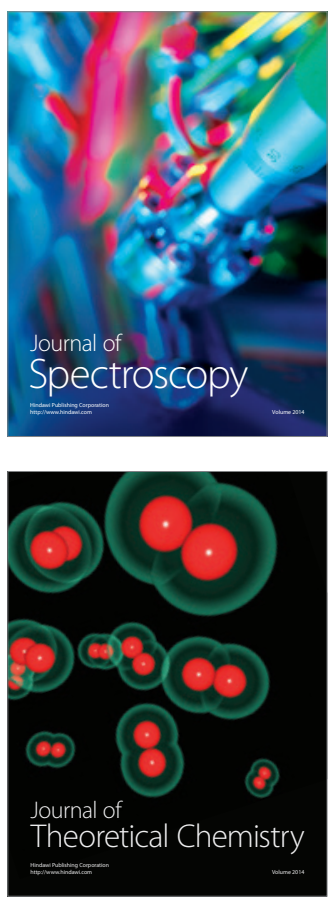
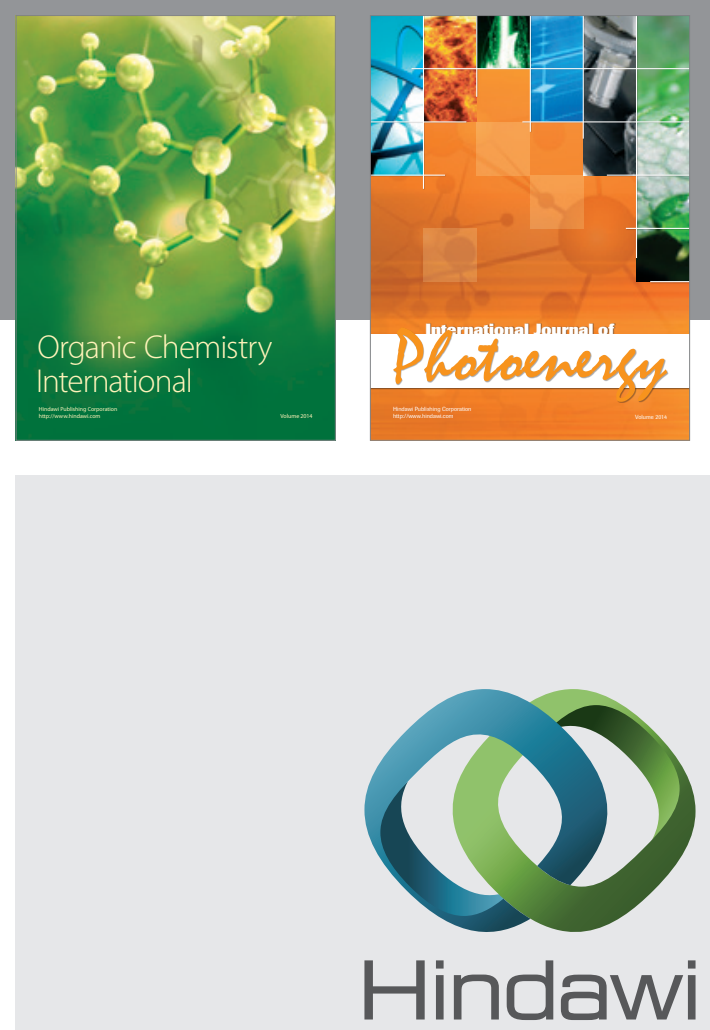

Submit your manuscripts at

http://www.hindawi.com
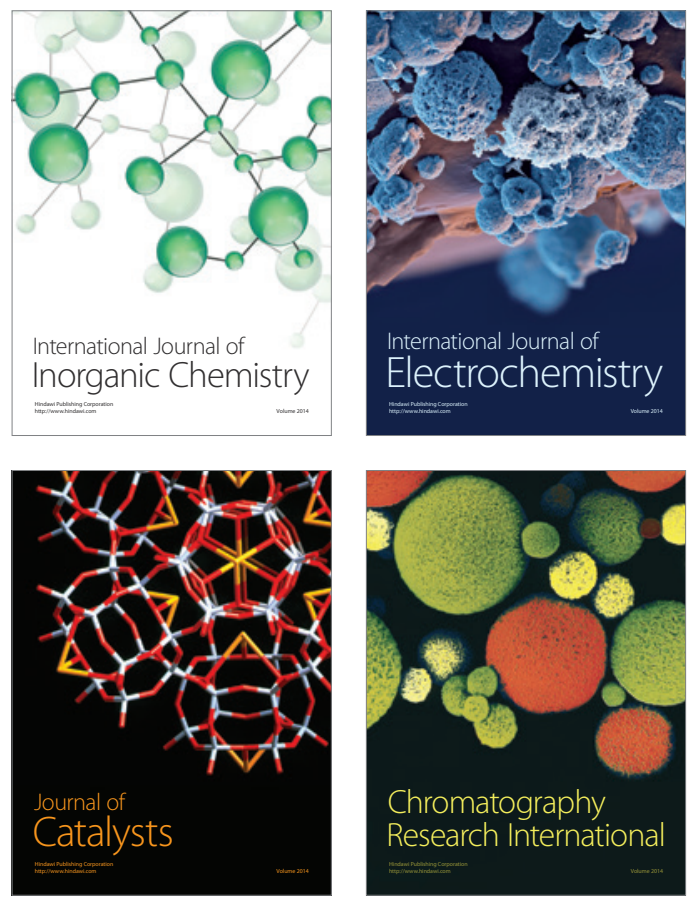
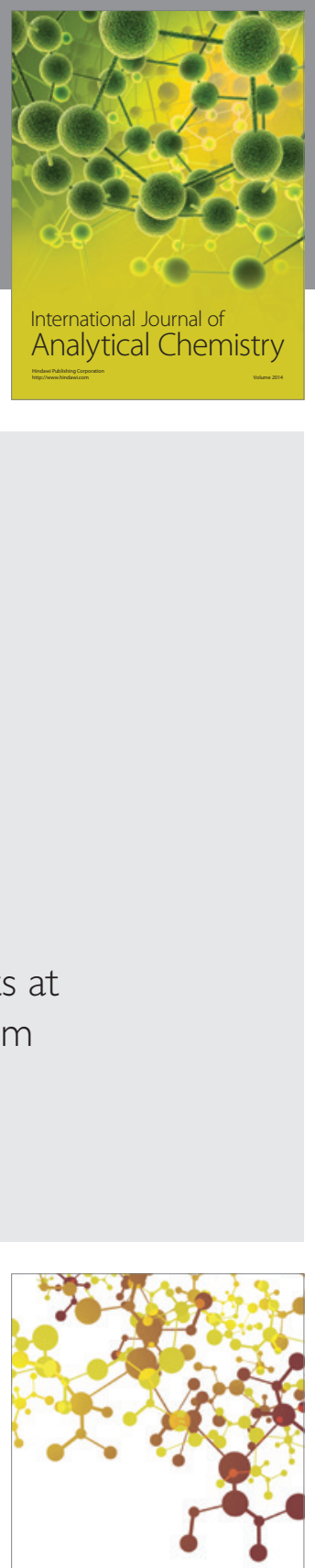

Journal of

Applied Chemistry
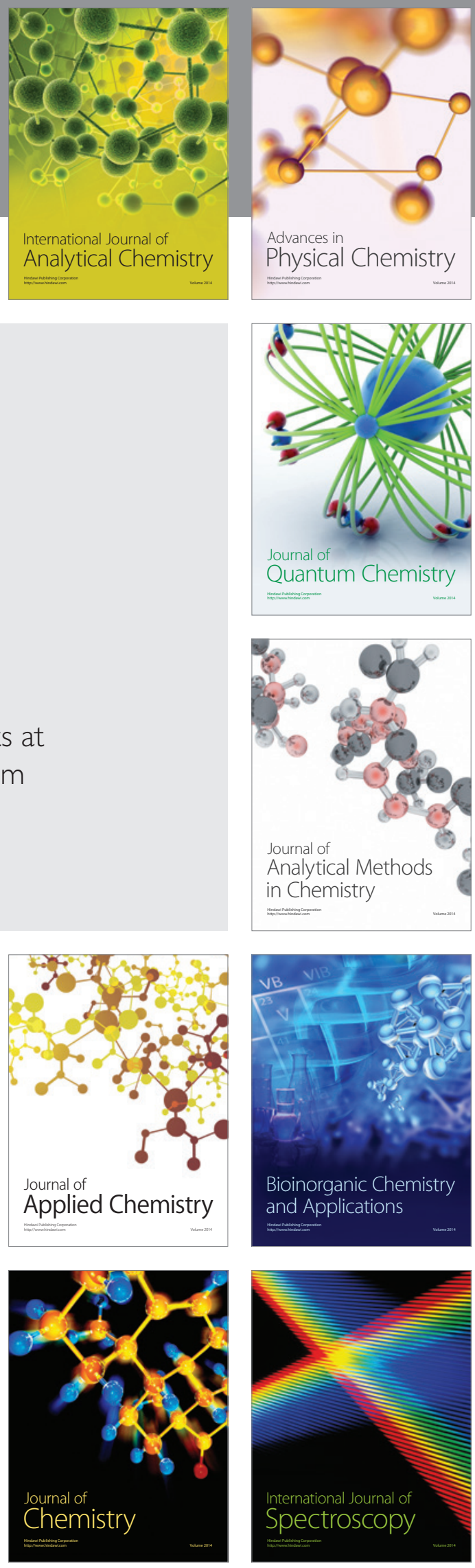